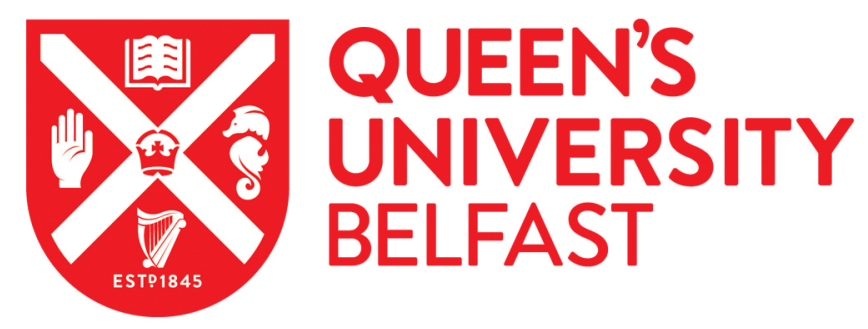

\title{
A Virtual Test System Integrating Materials and Manufacturing to Aid Design Choices
}

Price, M., Gonzalez-Murillo, C., Butterfield, J., Murphy, A., \& McCool, R. (2010). A Virtual Test System Integrating Materials and Manufacturing to Aid Design Choices. 1-10. Paper presented at 10th AIAA Aviation Technology, Integration, and Operations Conference, Fort Worth, Texas, United States.

Queen's University Belfast - Research Portal:

Link to publication record in Queen's University Belfast Research Portal

\section{General rights}

Copyright for the publications made accessible via the Queen's University Belfast Research Portal is retained by the author(s) and / or other copyright owners and it is a condition of accessing these publications that users recognise and abide by the legal requirements associated with these rights.

Take down policy

The Research Portal is Queen's institutional repository that provides access to Queen's research output. Every effort has been made to ensure that content in the Research Portal does not infringe any person's rights, or applicable UK laws. If you discover content in the Research Portal that you believe breaches copyright or violates any law, please contact openaccess@qub.ac.uk. 


\title{
A Virtual Test System Integrating Materials and Manufacturing to aid Design choices
}

\author{
M.A. Price, C. Gonzalez-Murillo, J. Butterfield, A. Murphy, R. McCool \\ School of Mechanical and Aerospace Engineering, Queens University, Belfast
}

\begin{abstract}
The rapid increase in usage of fiber reinforced, structural composites in commercial aviation and beyond is providing many challenges to designers in understanding how they can be used more effectively to exploit their advantages. One such challenge is in the appropriate selection of a composite lay-up or type which can be most efficient in a given application scenario. The difficulty lies in the variability that is possible in composite part production. Each new layup or configuration is effectively a new material and requires an extensive test programme to validate the performance, from coupons which give basic material characteristics, up through the test pyramid to large sub-components which contain basic assemblies. This variety of testing gives confidence in understanding the material and how it performs after processing in structural assemblies. Naturally the manufacturing process is also important here with different processes sometimes needed for different materials or thicknesses. However, inevitably this is a time consuming and expensive process requiring many thousands of small tests leading up to a few major tests which are complex to set up and perform. This work is attempting to address this by developing a virtual test system which will sit hand-in-hand with a physical test system. The concept is based on the performance of as many validated simulations as possible. These can subsequently be used for variants or derivatives to inform design choices and establish new validation programmes where appropriate.
\end{abstract}

\section{Introduction}

$\mathrm{T}$ he insatiable appetite for technology and the benefits to life it brings has created an expansion in consumption across the globe and a need for transport of goods and travel of people. The resulting energy usage in the manufacturing and transport sectors is very significant. Manufacturing generates about $25 \%$ of $\mathrm{CO}_{2}$ emissions in the developed countries. Interestingly the manufacturing process itself accounts for between $50 \%-90 \%$ of this output. The major implication is that while manufacturing and technology have a major impact on the wealth and well-being of society they are also responsible for a significant proportion of the damaging emissions produced. Moreover, it is the process, that is how goods are made, that lies at the heart of the issue.

There are substantial gains to be made focussing on the design and manufacture of the vehicles themselves. In particular the use of lightweight materials can make a major contribution to efficient operations by reducing fuel consumption. But lightweight materials, such as carbon fibre composites, are expensive to buy and process and many are not yet well understood. There are challenges in these materials in understanding their properties and performance is compounded by a need for new, more efficient, manufacturing processes and new end of life scenarios. Accounting for the whole life of a component is difficult even when the materials are well known, such as in metals, but it is clear that many questions for composites cannot be addressed with current design methods and procedures.

It is widely recognised that there is a failure to exploit the full benefit of the properties these materials. Often composite structures are designed as if traditional metal materials were being used [1, 2]. This "Black Metal" approach to design of components can only be overcome with new understanding and adoption of new design methods which account for the amazing range of materials and constructions available. The evolution of new design methods will set new manufacturing challenges which require advances to be made both in the technology to manufacture and techniques which produce at larger rates, get to market faster, with improved quality, reduced costs while remaining loyal to a sustainable agenda. This is a significant and demanding challenge. 
A key enabling technology to allow the integrated introduction of new processes, materials and configurations while at the same time, reducing development lead times, is computational science. A key benefit of computational technologies is their ability to break engineers' reliance on previous product experience and heuristic data, which of course will be limited for new configurations, materials and manufacturing methods. What is more, the use of simulation has the potential to address the seemingly competing manufacturing targets of improving product quality, reducing manufacturing cost and compressing the time to market. Moreover, manufacturing simulation has the potential to allow accurate assessment of the environmental impact and energy requirements of competing product designs, materials or processes.

For example, to produce a competitive airframe or busframe design, procedures must allow for the consideration of many diverse stages in the life cycle of the vehicle. In addition to satisfying the fundamental elements of designing for strength, stiffness and durability, vehicles must be designed to consider the efficiency of manufacture (Design for manufacture/assembly) and the efficiency of maintenance (Design for inspection/maintenance). For future composite vehicle frame designs, new design elements are required to allow designers to consider 'Design for recycling' or 'Design for disassembly'. However, to produce a truly 'green' aircraft or bus a more complete understanding is required. The key requirement of any design tool is to ensure that changes reduce the total impact on the environment, as opposed to simply transferring the burden to another stage of the life cycle.

The recent use by industry of product life cycle management (PLM) tools has increased [3], and some of the potential for addressing these issues is now recognised. But even though the capability and use of simulation has increased within latter design stages, the use of empirical and historical data for early design and manufacturing decisions has resulted in evolutionary development and has tempered the impact of new materials and manufacturing processes. The major challenge is therefore to remove the dependency on empirical and historical data and replace this with reliable, validated, simulation and predictive methods based on the attributes of the product and process under consideration. A full simulation thread is needed, and is currently missing.

Over the last 13 years a significant amount of research on aircraft stiffened panel design, analysis and manufacture has been undertaken at Queen's University Belfast. The majority of physical testing has focused on metallic structures with riveted and welded structures designed to have significant post-buckling strength. Research programmes examining panel analysis, optimization and methods of manufacture have all comprised experimental validation programmes. In addition, in order to maximize the value of these time consuming and expensive physical tests, corresponding computational simulations have been developed, which have then allowed a greater range of the design or manufacturing parameter space to be examined. This rich history of coupled physical test and simulation has allowed the development of robust idealization and solution procedures for aircraft stiffened panel buckling and collapse analysis. In addition, a detailed understanding on the associated requirements on physical tests and the benefits and limitations of the application of simulation methods has been established. Costs, both in terms of financial requirements for physical testing and computational costs in terms of model building and solution times have been systematically documented, allowing the benefits of an integrated approach to be quantified.

But more recently, the additional consideration of the manufacturing process has brought new challenges. It is evident that the higher levels in the test pyramid - the major structural sub-systems require proper manufacture. This implies that the material choice should also be informed by the manufacturing processes used and in fact, in design, such considerations are accounted for in design allowables and are a key limiting factor in the choice or usage of some materials.

Building on earlier work attempting to address these challenges the authors have enhanced their definition of virtual testing along with methods to design coupled physical and computational test programmes to ensure the validation of the concept by physical test and to maximize the findings with a given time and budget. Other attempts to build a virtual approach to test the material properties of structural components in aircraft were introduced a few years ago by Airbus, this work focused on testing entire assemblies or major components such as stiffened fuselage and stability panels $[4,5,6]$. 


\section{Virtual Test Strategy}

An integral part of any development programme is the validation of concepts and products. The systems engineering process which governs many larger scale projects particularly in aerospace, has verification and validation embedded in the process, as exemplified in the classic V diagram. Where all the technologies being incorporated into the system are known, the verification and validation focuses on the assembled system and its performance. But the integration of a new technology, such as a new material or processing method, brings additional uncertainty to the process. For example, the strength of a joint may be less clear with a new material or process and consequently additional testing, is required to reduce uncertainty and risk for the new system.

The recent expansion in the use and uptake of composite materials in major structures has exposed the time and cost needed to produce products which are safe and behave as designed in service. With metallic materials there has been a wealth of experimental testing completed over decades, and the resultant mine of data has meant that testing of the materials and sub-components could be kept reasonably minimal. The increase in use and application of composites has been such that this data mine has not been established, and the data which does exist is guarded well by companies as their intellectual property, and consequently the volume of tests needed for new products is very significant. It is estimated that tens of thousands of specimens are needed for a new aircraft wing. The costs and schedule impact of this volume of work is a serious issue and moreover is not likely to reduce in future programmes as the range of possibilities with composites brings new materials to the fore with each programme.

Virtual testing couples computational simulation techniques, physical testing methods and infrastructure to focus and multiply the value of a physical test programme. Simulation tools, such as Finite Element Analysis (FEA), are used to model the potential physical test programme and test variations prior to test programme definition. Using the preliminary computational data as a guide, the physical test programme is defined. Once a physical test element is completed and the simulation method validated, it may be used to expand, computationally, the range of parameters or test conditions studied. Key to making virtual testing work is the understanding of the 'user requirements' for the tests and the development and validation of robust and compatible simulation and experimental procedures. To supervise the process a systems engineering philosophy along with Design Of Experiments (DOE) tools may be applied, allowing the definition of the most effective test programme to accomplish the required purpose with the minimum time and/or cost. Virtual testing capability needs to facilitate the following broad aims:

1. Reduce the costs associated with testing in airframe configuration, materials and process development.

2. Facilitate the study of a wider range of parameters than occurs in a typical test programme, such that generic rules may be extracted if possible.

3. Facilitate understanding of structural behaviour, under a wide range of conditions.

A new approach to verification and validation of the materials is needed. Whilst it is still necessary to investigate behaviour from the small coupon scale up to full systems, a fresh view of the data extracted via testing and avenues for reduction in the number and range of tests need to be explored.

This work is building on a rich history of coupled physical tests and simulations which has allowed the development of robust idealisation and solutions procedures in structures.

A review of several test programmes undertaken previously $[7,8]$ by the team was carried out in the context of the standard range of material and structural test standards (ASTM) and the test pyramid. In this the data needed, the data gathered and the design requirements were all considered in evaluating the outputs from the test programme. The following initial observations have been made:

1. The higher levels in the test pyramid (major structural sub-systems) require proper manufacture. Therefore manufacturability and assembly characteristics should be considered in the material development.

2. Test Specimens cannot always reflect in-service conditions - so relevance of data is a key consideration.

3. Data acquisition and reduction must be concise and accurate but broad enough to allow development of generic guidelines.

4. Modelling must be carried out in parallel to support the computational studies and predictive methods. 
To address the observations the project is proceeding in three phases:

1. Develop an automated test simulation

A simple spreadsheet interface has been implemented to automatically generate simulation models of test specimens matching the first few ASTM tests (see Table 2). The application creates a starting geometry test piece with appropriate boundary conditions and carried out the test extracting the data automatically.

2. Map the data needed for standard design with the data obtainable from tests.

The standard tests have been documented with a corresponding list of test parameters and data, both input and output. The required data for service conditions for a given design will vary as will manufacturability. The manufacturability data is yet to be mapped.

3. Carry out validation studies to evaluate accuracy and develop statistical banks for future reference.

An initial validation set has been carried out with the basic fibre and matrix properties inserted to produce standard tensile and open hole tensile tests with good correlation (as would be expected).

Progress to date has already highlighted how quickly tests can be carried out over a range and the data stored for future reference. It has also shown that many tests can provide the same data so the opportunity exists to extract more data from a given test to reduce the overall set, as will be explained later. It is hoped to identify a minimal test set for given requirements on completion of the project.

\section{A. The Test Pyramid}

Historically, the process to validate composite material performance requires the following testing procedures on coupons of material layups. Performance metrics include tensile strength, flexural resistance, compressive strength, fatigue life and crack propagation among others. Basic subassemblies are next, following coupon testing. This stage includes joints and connections of the material laminates. Substructures would then be tested in order to validate the material. A typical large airframe (including tails, wing boxes and fuselage) requires $\sim 10^{4}$ tests including component and assemblies to achieve safety certification [9]. The building-block approach forms the classic test pyramid (Figure 1) with many more tests being carried out at the base (coupon) level than at the tip (full scale) level. This naturally reflects the greater uncertainty in testing new coupons and accounts for learning through these tests as only the most successful (appropriate) configurations are brought to the next level up.

The US Department of Defence (DOD) recommends the use of the building-block approach to validate composite structural designs [10]. This approach is often considered essential to the validation and/or certification of composite structures due to the sensitivity of composites to out-of-plane loads, the multiplicity of composite failure modes and the lack of standard analytical methods.

In more general terms, this building-block generates the material's basic values and design limits which will consequently permit the identification of critical areas for subsequent test validation. The approach also permits the determination of failure strengths for each design and the completion of more complicated tests that evaluate complex loading situations with the possibility of failure from several modes. Finally, using the approach permit us to compare to analytical predictions and adjust analysis models as necessary for a better design and conduct further testing for final validation of internal loads and structural integrity.

The virtual test simulations will need to replicate in a satisfactory way, the physical tests needed to validate composite material performance. As a result, the simulation has to be able to predict the non-linear loaddisplacement relationship and ultimate strength of the material. The great challenge here is to identify and incorporate into the simulator the many possible damage mechanisms so the model can correctly represent its effect on the progression to failure. 


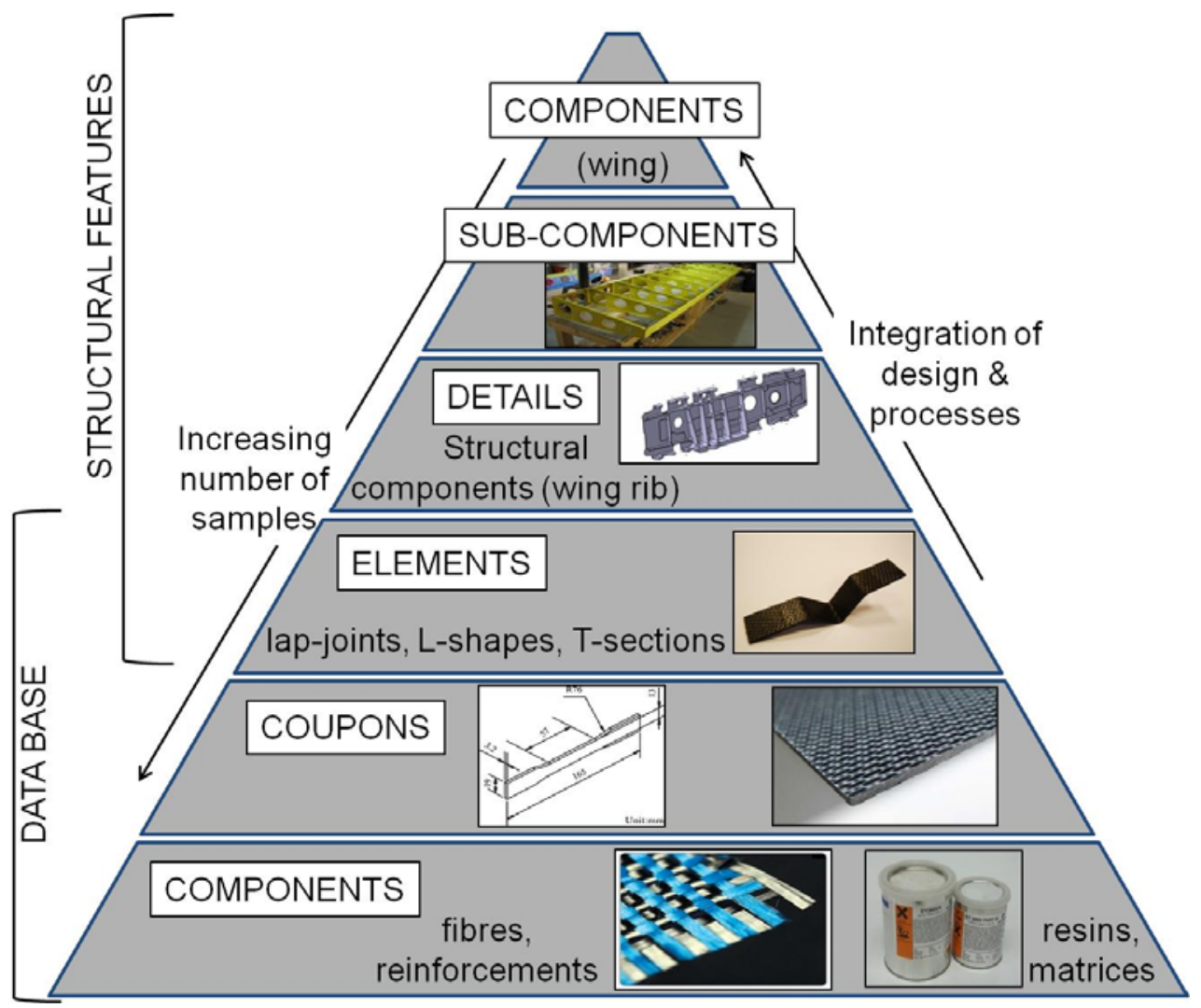

Figure 1 Building-block approach, adapted from MIL-HDBK-17.

Laminar stress analysis is very accurate for predicting load distributions throughout a composite assembly since its behaviour is linear-elastic. Once damage starts, the prediction becomes very difficult since the behaviour becomes non-linear starting at a micro scale (micro crack and micro fibre delamination) up to macro scale (crack propagation, debonding, delamination, bucking and so on). However, the recent advances in modelling, simulation and computational methods considering increasing realism in damage mechanisms at micro and macro scales. As the credibility of these models increases, the possibility of using simulations as virtual tests also increases, reducing with this the number of physical tests currently needed to achieve certification.

A virtual test has to consider the recommendations mentioned above and reproduce in satisfactory way complex fracture behaviour in any new composite material. As can be seen, structural complexity changes in each level of the pyramid, starting from single geometries at the bottom level to complicated components at the top. However, all six levels cover points included in Table 1.

\section{B. Implementation Strategy}

At this point, the virtual test relies entirely in how to approach the failure behaviour of a composite material. Table 1 illustrates the additional complexity in the case of composite laminates highlighting the need for consideration of a scale lower than the typical test coupons for metallic materials. The question now arises as to whether the process should start from the very bottom of this, at fibre and matrix level, or from the top at component level. In practice testing is carried out from the bottom up but the test programmes are most often designed with the end application in mind, as there is always a driver for the introduction of a new material or process.

In this context, the bottom-up method, would seek to simulate failure behaviour by constructing detailed micro scale models and then it will incorporate increasing realism. The difficulty of using this method is that it requires the use 
of time intervals and specimen scale which often remain below the duration of a test and the size of a structural test coupon. For instance, if we consider a structure, the fracture behaviour that can be predicted by the model during a simulation analysis cannot be guaranteed to be exhaustive of those that arise in long duration tests or large-scale components.

Table 1 Structural complexity levels of the building-block approach.

\begin{tabular}{|l|l|}
\hline Constituent Testing & $\begin{array}{l}\text { Evaluates the individual properties of fibres, fibre } \\
\text { morphology, matrix materials, and fibre-matrix } \\
\text { preforms. Including, fibre and matrix density, and fibre } \\
\text { tensile strength and tensile modulus. }\end{array}$ \\
\hline Lamina Testing & $\begin{array}{l}\text { Evaluates the properties of the fibre-matrix interaction in } \\
\text { the composite material. Including, fibre weight, volume } \\
\text { fractions, void content, cured ply thickness, lamina } \\
\text { tensile strengths and moduli, lamina compressive } \\
\text { strengths and moduli, and lamina shear strengths and } \\
\text { moduli. }\end{array}$ \\
\hline Laminate Testing & $\begin{array}{l}\text { Characterises the response of the composite material in a } \\
\text { given design. Properties include tensile strengths and } \\
\text { moduli, compressive strengths and moduli, shear } \\
\text { strengths and moduli, interlaminar fracture toughness, } \\
\text { and fatigue resistance. }\end{array}$ \\
\hline $\begin{array}{l}\text { Structural Element } \\
\text { Testing }\end{array}$ & $\begin{array}{l}\text { Evaluates the ability of the material to stand common } \\
\text { laminate discontinuities. Properties include open and } \\
\text { filled hole tensile strengths, open and filled hole } \\
\text { compressive strengths, compression after impact } \\
\text { strength, and joint bearing and bearing bypass strengths. }\end{array}$ \\
\hline $\begin{array}{l}\text { Structural } \\
\text { Subcomponent } \\
\text { higher) Testing }\end{array}$ & $\begin{array}{l}\text { Evaluates the behaviour and failure mode of increasingly } \\
\text { more complex structural assemblies. }\end{array}$ \\
\hline
\end{tabular}

On the other hand, the top-down method focuses on an engineering need and seeks always to satisfy the constrains imposed to the physical structure. This method begins with a macro scale model, which progressively would be augmented by the incorporation of successive details needed to be considered in the tests. Here, the model is always calibrated against the physical tests applied to the specimens, and therefore, predictions of failure behaviour are available at any stage. This characteristic of continually producing validation predictions against physical tests permits the identification of the parameters that have an important effect on the performance of composite structures.

Considering the two models mentioned above, a combination of both approaches fits better into our concept of virtual test. Therefore, the virtual test proposed in this research works with the top-down method of the initial level before going up to the upper level of the testing pyramid. For instance from the coupon level of the pyramid, the virtual test will analyse the behavior of the material by going down into its fracture behavior before passing up to the elements level and so on.

The virtual test proposed will also serve as an accurate interpolator between relatively sparse data accumulated by real physical tests. The interpolation could, for example, span deviations from the physical test matrix in ply layups or stress concentration areas to mention some. Ideally, the virtual test simulations might substitute many of the physical tests required for component design and validation, using the remaining physical tests to calibrate the virtual tests and establish its validity.

After describing the virtual test, it is clear that a link between models and experiments are the central part of the virtual test. Experimental limitations on failure behaviour and damage mechanisms impose a rigid bond on what is achievable in a virtual test. The link between models and experiments will be explained in the following section. 


\section{Model and Experiment Feedback}

The construction of material models has been analysed by several authors in the past [11, 12, 13]. The essential link needed is to identify appropriately certain properties of the material and the phenomenon of interest and accept the fact that feedback is needed from both the results from the real tested samples and the results from the FE simulations. Only after the virtual test receives feedback does it start the process of validation and pass on to more complex simulations such as the incorporation of more details into each FE model (i.e. non-linearity or failure mechanisms at micro scale). At this prototype phase, the virtual test has to consider the experimental validation as its strongest influence tool since it entirely relies on the ability to match the results of tested material with the simulation values before testing different material configurations (varying ply lay-ups or fibre/matrix components) or predicting failure behaviour, strength and fatigue lifetime.

The virtual test will need to follow a formal approach in order to be calibrated against experimental procedures. Here simple curve fitting may not be sufficient. The inverse problem method is often used to infer a model parameter from experimental data $[14,15]$. The inverse problem approach frequently incorporates regularisation to treat the effects of noise in the parameter validation. The outcome of the regularisation calculation is a quantitative estimation of the degree to which the parameter can be determined. Thus this formal analysis quantifies the degree to which mechanisms and parameters have an influence on the experiments and if the parameters cannot be determined because of noise, the measurable outcome of the experiment has no information in it that determines the parameter. In other words, the parameter is not relevant to the engineering property being measured.

\section{Implementation}

In recent decades, carbon fibre composites became the first choice for replacing metallic alloys in large commercial aircraft structures, from ailerons and flaps to large parts of fuselage and wings in the new generation of aircrafts. In the strongest composite materials, fibres are unidirectionally distributed in plies and then several additional plies are stacked in different directions so the composite can support high levels of stiffness and strength. Many of the failure mechanisms in polymer composite laminates are well known due to many decades of testing. For the task of identifying failure mechanisms, destructive sectioning before reaching ultimate failure is often acceptable. Optical and scanning electron microscopy follows, and these reveal details at micro scales. Identified failure mechanisms include among others, delamination, cracks in the loading direction, transverse microcracking, microbuckling effect of aligned fibres under compression, buckling (in individual plies or globally), debonding of the fibre-matrix interface and fibre rupture.

\section{A. Standard Experiments}

In this research, for validation using physical test, eleven critical procedures needed to obtain the main mechanical properties of a composite material, were identified. All of these tests are based on the standards recommended by the ASTM. Another test (Seven-Point Bending) is proposed in this study since it is believed that this test will provide substantial results, but this is yet to be explored. The twelve test mentioned previously are summarized in Table 2 , and as mentioned in previous sections, these tests comprehend an extensive validation programme from coupons to basic assemblies.

\section{B. Virtual Test Implementation}

The next natural step in the virtual test project is to create a computer program which simulates the standard tests but considers the following points:

1. Consider all the testing procedures mentioned above.

2. Includes functionality to change mechanical properties and material configurations when required e.g. number of plies, ply orientation.

3. Replicates the geometry of testing samples in a CAD file so it can be used for FEA.

4. Be able to produce reports based on the FEA. 
Table 2 Summary of testing procedures.

\begin{tabular}{|c|c|c|c|c|}
\hline & Test standard & Name & Test output & $\begin{array}{c}\text { Simulation } \\
\text { output }\end{array}$ \\
\hline 1 & ASTM D3039 & $\begin{array}{l}\text { Standard Test Method for Tensile Properties of Polymer } \\
\text { Matrix Composite Materials }\end{array}$ & $\mathrm{F}_{\mathrm{tu}}, \varepsilon_{\mathrm{i}}, \mathrm{E}_{\text {chord }}^{\mathrm{t}}$ & $\begin{array}{l}\mathrm{X}_{\mathrm{T} 1}, \mathrm{X}_{\mathrm{T} 1 \varepsilon}, \mathrm{E}_{\mathrm{T} 1}, \\
\mathrm{E}_{\mathrm{T} 2}, \mathrm{U}_{12}, \mathrm{U}_{21}\end{array}$ \\
\hline 2 & ASTM D7264 & $\begin{array}{l}\text { Standard Test Method for Flexural Properties of Polymer } \\
\text { Matrix Composite Materials }\end{array}$ & $\sigma_{f M}, \sigma_{f B}, E_{B}, E_{f}$ & \\
\hline 3 & ASTM D7078 & $\begin{array}{l}\text { Standard Test Method for Shear Properties of Composite } \\
\text { Materials by V-Notched Rail Shear Method }\end{array}$ & $\begin{array}{l}F^{\mathrm{u}}, \tau_{12}{ }^{\mathrm{m}}, \mathrm{Y}_{12}{ }^{\mathrm{m}}, \\
\mathrm{G}_{12}{ }^{\text {chord }}, \mathrm{F}_{12}{ }^{\mathrm{m}}\end{array}$ & $\mathrm{S}_{\mathrm{s}}, \mathrm{G}_{12}$ \\
\hline 4 & ASTM D6641 & $\begin{array}{l}\text { Standard Test Method for Compressive Properties of } \\
\text { Polymer Matrix Composite Materials Using a Combined } \\
\text { Loading Compression (CLC) Test Fixture }\end{array}$ & $\begin{array}{l}F_{c u}, \varepsilon_{i}, E_{c h o r d}^{c} \\
u\end{array}$ & $\begin{array}{l}\mathrm{X}_{\mathrm{C} 1}, \mathrm{X}_{\mathrm{C} 1 \varepsilon}, \mathrm{E}_{\mathrm{X} 1}, \\
\mathrm{E}_{\mathrm{X} 2}, \mathrm{U}_{12}, \mathrm{U}_{21}\end{array}$ \\
\hline \multirow{2}{*}{5} & ASTM D6671 & $\begin{array}{l}\text { Standard Test Method for Mixed Mode I-Mode II } \\
\text { Interlaminar Fracture Toughness of Unidirectional Fiber } \\
\text { Reinforced Polymer Matrix Composites }\end{array}$ & $G_{c}$ & \\
\hline & ASTM D5528 & $\begin{array}{l}\text { Standard Test Method for Mode I Interlaminar Fracture } \\
\text { Toughness of Unidirectional Fiber-Reinforced Polymer } \\
\text { Matrix Composites }\end{array}$ & & \\
\hline 6 & ASTM D5766 & $\begin{array}{l}\text { Standard Test Method for Open-Hole Tensile Strength of } \\
\text { Polymer Matrix Composite Laminates }\end{array}$ & $\mathrm{F}_{\mathrm{x}}^{\mathrm{OHTu}}$ & \\
\hline 7 & ASTM D6484 & $\begin{array}{l}\text { Standard Test Method for Open-Hole Compressive } \\
\text { Strength of Polymer Matrix Composite Laminates }\end{array}$ & $\mathrm{F}_{\mathrm{x}}^{\mathrm{OHCu}}$ & \\
\hline 8 & ASTM D7137 & $\begin{array}{l}\text { Standard Test Method for Compressive Residual } \\
\text { Strength Properties of Damaged Polymer Matrix } \\
\text { Composite Plates }\end{array}$ & $\mathrm{F}_{\mathrm{CAl}}, \mathrm{E}_{\mathrm{CAl}}$ & \\
\hline \multirow{2}{*}{9} & ASTM D6671 & $\begin{array}{l}\text { Standard Test Method for Mixed Mode I-Mode II } \\
\text { Interlaminar Fracture Toughness of Unidirectional Fiber } \\
\text { Reinforced Polymer Matrix Composites }\end{array}$ & $G_{c}$ & \\
\hline & ASTM D5528 & $\begin{array}{l}\text { Standard Test Method for Mode I Interlaminar Fracture } \\
\text { Toughness of Unidirectional Fiber-Reinforced Polymer } \\
\text { Matrix Composites }\end{array}$ & & \\
\hline \multirow[b]{2}{*}{10} & ASTM D5868 & $\begin{array}{l}\text { Standard Test Method for Lap Shear Adhesion for Fiber } \\
\text { Reinforced Plastic (FRP) Bonding }\end{array}$ & & \\
\hline & ASTM D3163 & $\begin{array}{l}\text { Standard Test Method for Determining Strength of } \\
\text { Adhesively Bonded Rigid Plastic Lap-Shear Joints in } \\
\text { Shear by Tension Loading }\end{array}$ & & \\
\hline 11 & ASTM D7137 & $\begin{array}{l}\text { Standard Test Method for Compressive Residual } \\
\text { Strength Properties of Damaged Polymer Matrix } \\
\text { Composite Plates }\end{array}$ & $\mathrm{F}_{\mathrm{CA}}, \mathrm{E}_{\mathrm{CAI}}$ & \\
\hline 12 & & Seven-Point Bending Test & & \\
\hline
\end{tabular}

The virtual test program started at the base of the pyramid, following the hierarchy mentioned before and the testing procedures mentioned in Table 2. The initial step then was to create a virtual environment for testing a coupon of composite laminate in tension so that an FEA model could produce results of maximum stress and strain as well as visual suggestion of where the stress concentration and crack initiation areas where concentrated. Figure 2, shows an image of the virtual test prototype program. From the image it can be seen that the virtual test prototype program includes a section where it shows basic information of the testing procedure based on the ASTM D3039, the measurements of the coupon as described in the standard and some other interactive fields where we can input the number of plies we want to add to our specimen as well as some mechanical properties of the material we want to analyse. At the very bottom of the program screen, there are also two buttons, one to start the FEA and another one to produce a report that contains images obtained from the FEA and also numerical results of each elements contained in the Finite Element (FE) model.

In order to calibrate the virtual test prototype program, physical tests were performed on specimens prepared according to the ASTM D3039 specifications, the mechanical properties and ply orientations (obtained from the composite manufacturer's data sheet) were fed into the virtual test program, the results were compared and the model calibrated.

The virtual test program captures the basic data needed from a form or a spread sheet as shown in Figure 2. This data is then transferred to a code which can be then accessed and used by Finite element analysis software. Part of the code created also includes the application of boundary conditions and loads so it replicates the physical testing conditions which the specimens are subjected to. After all the parameters are inserted into the code, a job is created 
by the software and its submission proceeds to obtain the results. Reports are produced in a different file but a summary of the most important results are displayed in the results form (Figure 3).

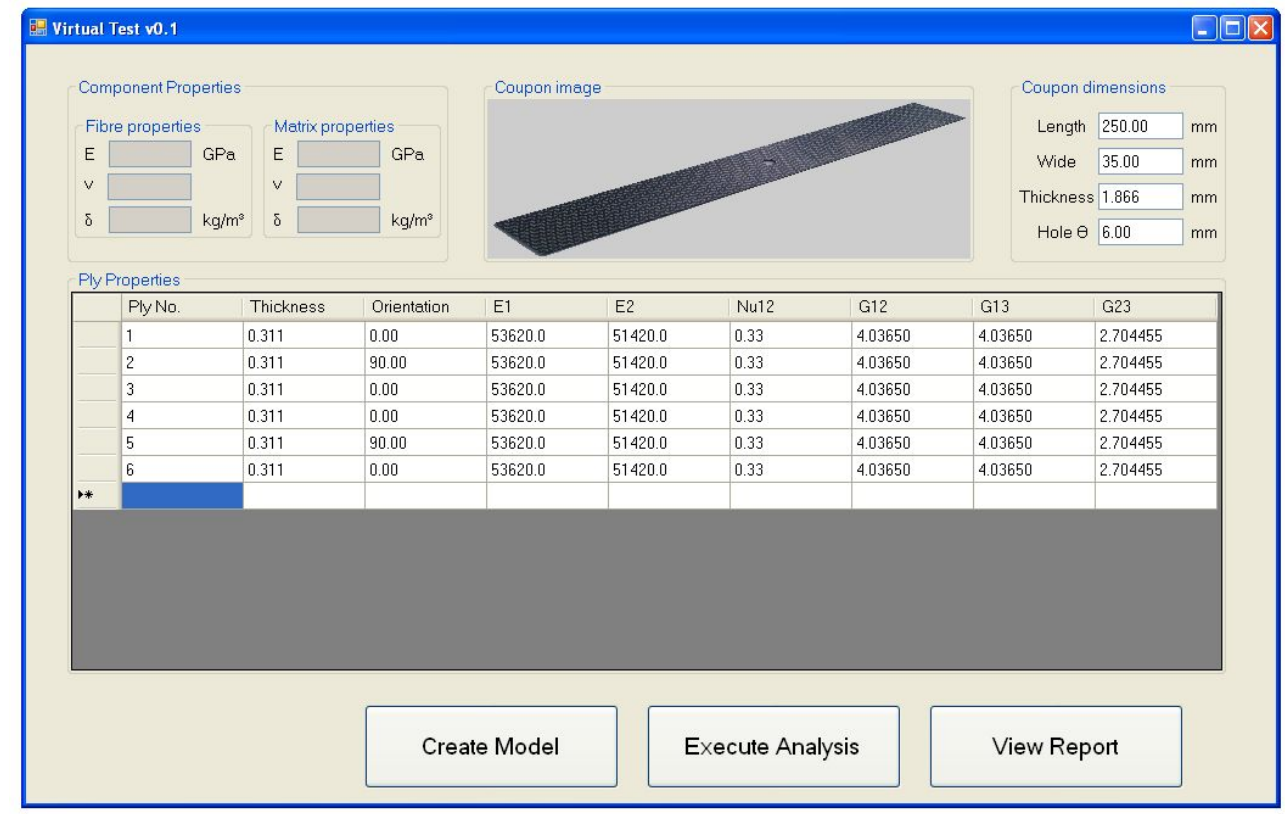

Figure 2 Virtual test program.

The analysis performed in Figures 2 and 3 represents a carbon fibre laminate material coupon test with 6 plies orientated as $0^{\circ} / 90^{\circ}$. It was decided to perform the test on open hole samples as per ASTM D5766 because this feature is commonly cut into composite structures to accommodate fasteners, hydraulics and electrical wiring, among others. Also, because from this test the experimental tensile parameters can be obtained (obtained using the ASTM D3039 test). This is an important point to highlight because with this, we can reduce the number of testing procedures for validating a new composite material. The stress concentrators and potentially the lateral edges of the specimen are sites at or near which damage is likely to initiate.

The failure behavior illustrated in Figure 3 is one of the most important common behaviors obtained under a tensile loading condition. This includes splitting cracks, which subsequently develop into shear failures in the form of ply delamination and cracks running in the fibre direction within individual plies.

The failure mechanisms mentioned above have very important effects on the load that the composite supports for a given boundary displacement. Fibre fracture and splitting as well as ply delamination (which has not yet occurred in Figure 3) precede the ultimate failure of the composite. As mentioned at the end of section II.B, There are some minimum conditions needed for a simulation to be sufficiently realistic. In other words the virtual test needs to use a top-down method in this level to predict and analyse the evolution of fibre fracture, splitting cracks and ply delamination for arbitrary loads, different ply orientations, and shape of the stress concentrators before passing to the next upper level (bottom-up method).

The FE model incorporated into the virtual test needs to be calibrated before it is used for forecasting composite laminate behavior. Calibration of the model requires actual data of all the inputs of physical samples tested. The parameters to be calibrated include the data base derived from the input form, the mechanical properties of the material (including fibre and matrix properties), geometry of the coupons or the shapes to be simulated, errors in the measurement of input values in the physical tests (including measurements of strain gages or stress-strain calculations), boundary conditions to which the coupon is subjected to (including fixation mechanisms, symmetry and displacements), loads and forces acting on the specimens and the incorporation of partitions onto the specimens in order to refine the meshes generated on the specimens. 
Once the model is calibrated to a reasonable value for an analysis another simulation has to be run on the specimen and a comparison of the results should be done before using the simulator with another material properties, this is the validation process.

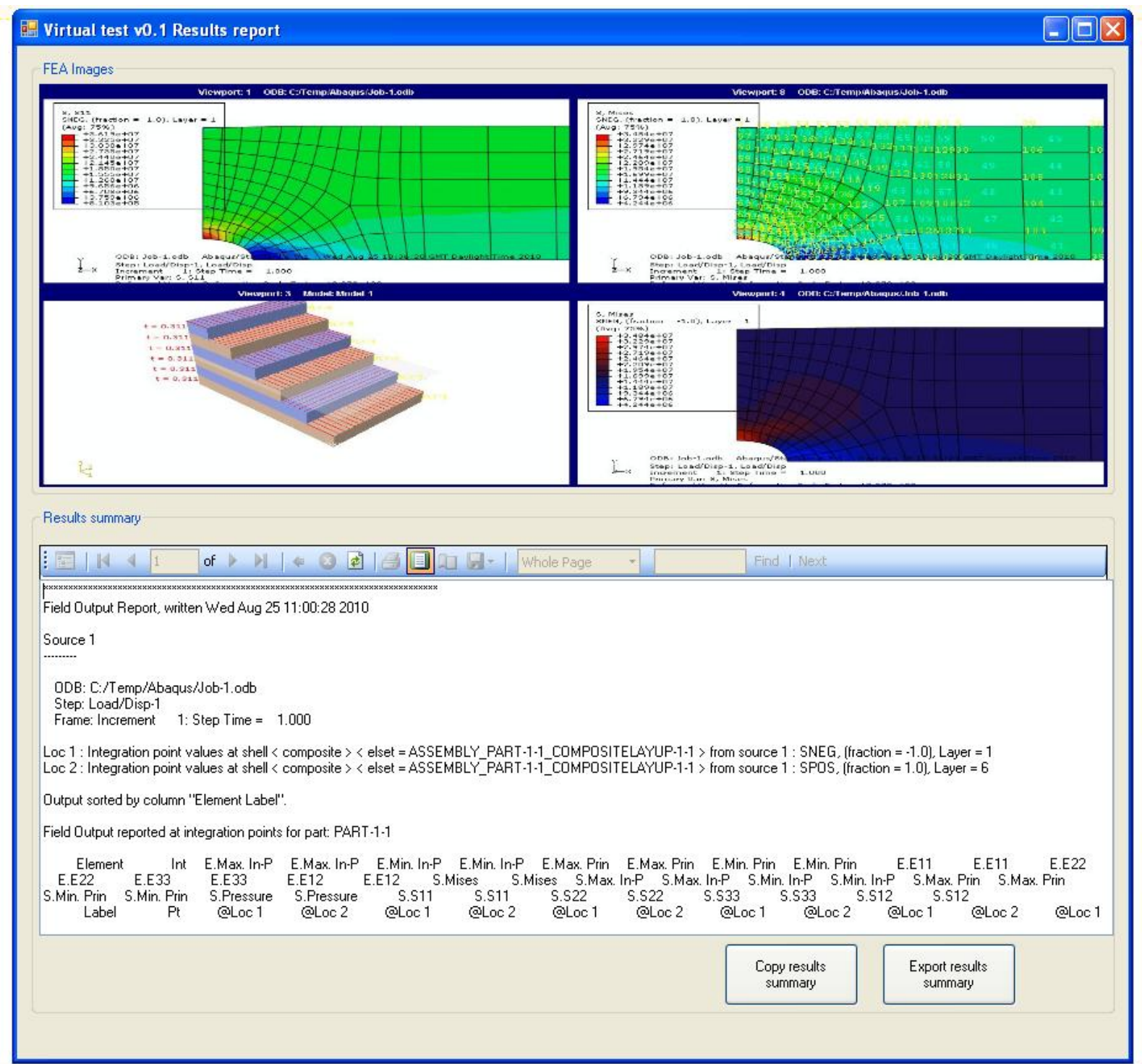

Figure 3 Virtual test program results form.

\section{Discussion}

The long term aim of this work is to provide a virtual test environment within which many more configurations can be compared before a final focused set of tests are carried out. In order to achieve this main goal there is a need to build a model for the different testing procedures listed in Table 2 and in the testing pyramid. 
In order to progress upwards to the apex of the testing pyramid, the composite virtual test started at the coupon level by simulating a preconsolidated material (Tencate Cetex, CF/PPS) with the mechanical properties provided by the manufacturer. The ability to simulate the tensile test for coupons offered several advantages such as reduction of costs, time savings and the comparison serves as validation for the virtual test for its future use in other contexts.

Another aim to consider in the virtual test environment is related to the data acquisition and subsequent reduction which must provide accurate and concise information. The preliminary simulation was backed up with a tensile test of coupons following the ASTM D5766 standard for open hole tensile strength. The physical test provided feedback to calibrate the simulator. The simulator is based on code created from data introduced into a form (Figure 2) and this data is then transformed to a Python code which subsequently will run a series of tasks and analyses in Abaqus 6.9 CAE.

The model starts by creating the geometric shape of the coupon by obtaining it dimensions from the data form. As it was identified, there were some areas where a refined analysis was needed, even for these simple geometry coupons, these areas were critical configurations corresponding to stress concentration zones in the coupons (representing holes for fixation of panels or in a subassembly). The model then creates partitions to the geometry to facilitate the analysis. Linear shell elements with reduced integration are selected by default, but these can be modified or replaced by other elements. Modelling of the layup for the composite structure can be performed according to the values obtained from the data form (Figure 4).

The material properties from the data form are added to the model at this point. These properties are added into the model using the composite layup tool included in Abaqus and it uses the shell elements mentioned before. The composite layup tool is very useful to add plies as required and the properties can be easily changed. Composite shell sections are appropriate to define a lay-up consisting of an arbitrary number of individual layers with isotropic or orthotropic material properties. For unidirectional laminates the orthotropic response of the undamaged material is assumed to be linearly elastic [16]. If damage has to be considered, it can occur by any of four different failure modes: fibre failure in tension, fibre buckling or kinking in compression, matrix cracking under transverse tension and shearing and matrix crushing under transverse compression and shearing $[17,18]$.

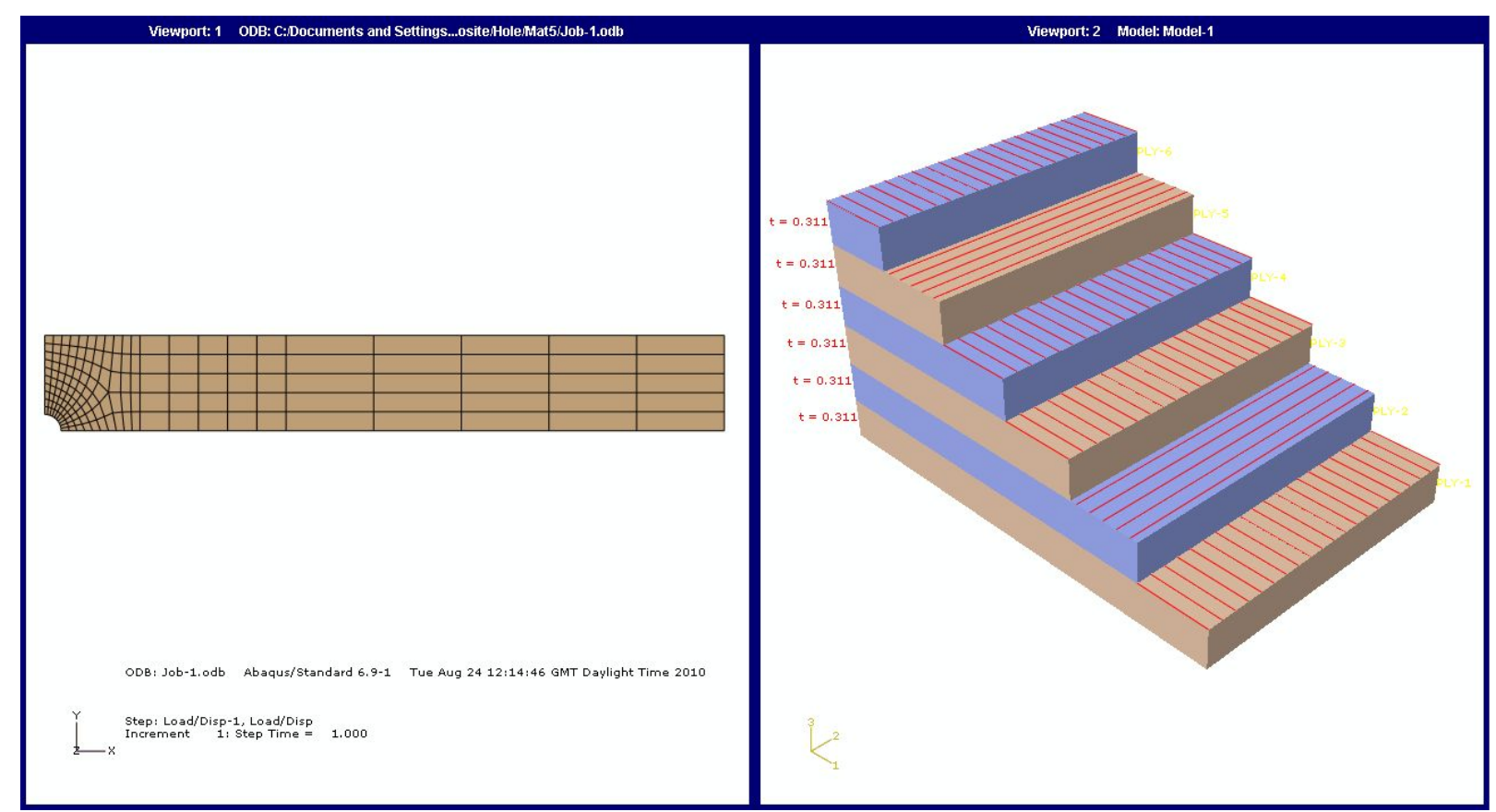

Figure 4 Left, mesh generated on a quarter of a composite coupon and right, layup of the composite coupon.

The application of boundary conditions and loads follows the sequence in the virtual test program. The creation of a mesh in the geometry is the last step the simulator does before submitting the job to analysis. After the mesh is 
created a solution is carried out with the Abaqus solver although at this point the virtual test simulator is only working for linear analysis.

Repeated simulations with different load ratios may then result in an interaction curve, such as the one shown in Figure 5. For a coupon not previously simulated, the results may need adjustments, which will have to be investigated and understood by comparison with the experimental test results. With this, values close to the test values should be obtained. Usually, the common reasons to find deviations in the results are due to the incorrect application of boundary conditions and load introduction. A different composite configuration should then be possible to simulate with good agreement with no significant adjustments to the model.

The results from the FEA simulations show that the model is behaving similarly to the physical test. Initial model parameters were input based on crude material properties. The virtual test simulations using the calibrated value parameters compared very well with the trend of the physical test and illustrate the predictive capability of the virtual test model. There is also a good agreement in the failure loads in physical tests and simulations.

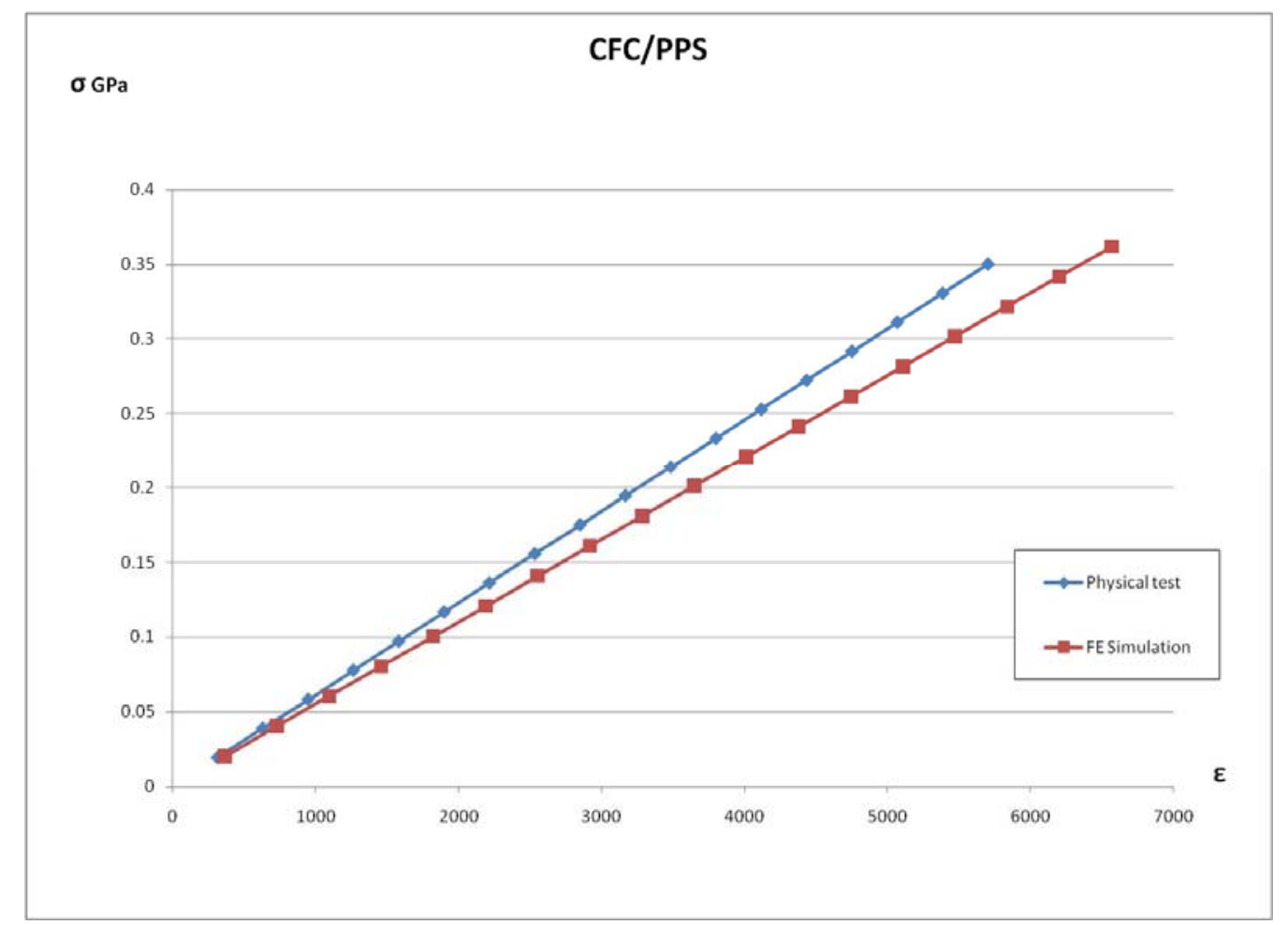

Figure 5 Stress-stain curves of physical tests and repeated simulations with different loads applied.

Reducing the testing procedures is another aim of this project and it is important to identify that some tests produce the same experimental parameters.

\section{Concluding comments}

In this research it was shown how a virtual test for the simulation of composite laminated coupons loaded in tension was developed. The virtual test is a system formed by a series of simulation models and laboratory tests linked by statistical and decision theory tools. Only when we achieve the point of putting all these tools to work together the virtual test can then substitute the physical testing of large amount of real specimens. Other efforts to develop virtual tests for composite materials are also being pursued, but that research is based mainly on frames and stiffened panels. Advances in modelling, computation and experimental techniques over the past two decades make the development of a virtual test a realistic goal; the major new challenge is achieving the integration of the necessary 
disciplines and because of the potential of the virtual test it can be predicted that it will help in reducing dramatically the costs and times involved in the validation of any new composite material in the aerospace industry.

The simulation results of the developed FE model agree well with the test results of the real samples. However, during the solutions it was noticed that the model react very sensitively to changes in the boundary conditions. The behaviour of the laminated layered shell in the model seems to be adequate in the calculated examples.

The virtual test environment will serve as a good tool for facilitating the design and manufacture of structural components formed with new composite materials validated with the FE simulations in the virtual test. It will also help to choose where to locate different configuration of materials in an assembly according to specific needs such as stiffer reinforcements in the assembly or transition panels between metallic and composite components.

\section{Further work}

- $\quad$ The immediate work to proceed in the virtual test will be to optimize the simulator so it can be precisely calibrated and tested with more physical samples.

- Simulate the rest of the tests mentioned in Table 2 and then start escalating up on the levels of the testing pyramid.

- $\quad$ Other disciplines such as statistics, decision making theory, and physics, must be brought into the virtual test environment.

- Further work on the calibration may focus on the automation of mesh refinement to provide resolution of more detailed regions on a specimen.

- The virtual test should include the incursion into micro scale experiments to analyse fracture behaviour of composite laminates and be able to make accurate predictions of materials failure.

\section{Acknowledgements}

The authors would like to thank the Department of Employment and Learning (Northern Ireland) and Queens University for their generous support of this project. Thanks are also due to members of the research team Ryan Wilson and Joao Pedro Serra e Moura for their contributions to this research and for providing the test results used to validate the virtual test.

\section{References}

1. Barbero, E. J., 1999, Introduction to Composite Materials Design (Materials Science \& Engineering Series), Taylor \& Francis, Philadelphia, Pa.

2. Gurdal, Z., Haftka, R. T., Hajela, P., 1999, Design and Optimization of Laminated Composite Materials, John Wiley \& Sons, Canada.

3. Komninos, I., 2006, Product Life Cycle Management, Urban and Regional Innovation Research Unit report.

4. Linde, P., Schulz, A., Rust, W., 2006, Influence of Modelling and Solution Methods on the FE-simulation of the Post-buckling Behaviour of Stiffened Aircraft Fuselage Panels, Composite Structures, Vol. 23, pp. 229-236. 
5. Linde, P., Pleitner, J., Rust, W., 2004, Virtual Testing of Aircraft Fuselage Stiffened Panels, Proceedings of the $24^{\text {th }}$ International Congress of the Aeronautical Sciences (ICAS 2004), Yokohama, Japan.

6. Mocker, T., Linde, P., Kraschin, S., Goetz, F., Marsolek, J., Wohlers, W., 2009, Abaqus FEM Analysis of the Postbuckling Behaviour of Composite Shell Structures, Internal report, Cocomat, Germany.

7. Murphy, A., Price, M., Gibson, A., 2006, Toward Virtual Testing of Airframe Stiffened Panels, Royal Aeronautical Society, Structures and Materials Group Conference on Virtual Testing, 25th-26th October, Hamilton Place, London.

8. Murphy, A., Price, M., 2006, Integrated Experimental and Computational Testing of Aerospace Stiffened Panels: Toward Virtual Testing, NAFEMS Seminar, Simulation versus Test, Cheshire, UK, 8 Nov.

9. Fawcett, A., Trostle, J., Ward, S. 1997, 777 empennage certification approach. 11th International Conference on Composite Materials. Australia: Technomic.

10. US Department of Defense MIL-HDBK-17-1F, 2002, Composite Materials Handbook, Vol. 1 Polymer Matrix Composites Guidelines for Characterization of Structural Materials. Department of Defense Handbook.

11. Ashby, M. (1992). Physical modelling of materials problems. Materials Science and Technology, Vol. 8, 102-111.

12. Gibson, R. F., 1994, Principles of Composite Material Mechanics, McGraw-Hill, New York.

13. Mahnken, R., Stein, E., 1996, A Unified Approach for Parameter Identification of Inelastic Material Models in the Frame of the Finite Element Method, Computer Methods in Applied Mechanics and Engineering, Vol. 136, pp. 225-258.

14. Kozhanov, A. (1999). Composite Type Equations and Inverse Problems. Utrecht, The Netherlands: VSP.

15. Tarantola, A. (2005). Inverse Problem Theory and Methods for Model Parameter Estimation. Philadelphia, PA: SIAM.

16. Megnis, M., Brondsted, P., Mikkelsen, L. P., 2004, Damage Evolution in Laminated Composite Materials, Somers, M.A.J. (eds.), Materilas Research Department, Riso National Laboratory, pp. 33-42.

17. Hashin, Z., 1980, Failure Criteria for Unidirectional Fibre Composites, Journal of Applied Mechanics, Vol. 47, pp. 329-334.

18. Kortschot, M. T., Beaumont, P. W. R., 1990, Damage Mechanics of Composite Materials: I Measurements of Damage and Strength, Composite Science and Technology, Vol. 39, pp.289-301. 